\title{
A RAINFALL SIMULATION STUDY OF EROSION OF SOME CALCAREOUS SOILS
}

\section{D.G. DIMOYIANNIS 1 ,* \\ S. VALMIS ${ }^{2}$ \\ P. VYRLAS 1}

\author{
${ }^{1}$ National Agricultural Research Foundation \\ Institute of Soil Classification and Mapping \\ Theofrastou 1, 41335 Larissa, Greece \\ ${ }^{2}$ Agricultural University of Athens \\ Iera Odos 75, Votanikos \\ 11855 Athens, Greece \\ * to whom all correspondence should be addressed \\ tel.:+30 - 410 - 660570; fax:+30 - 410 - 66071 \\ e-mail: iscml@bee.gr
}

Received: 29/11/01

\begin{abstract}
In order to study the erodibility characteristics of some calcareous soils from Central Greece, the instability of aggregates of 2.0-4.7 mm in water was studied. Soil loss experiments were also conducted in the laboratory using a rain simulator where soil loss was measured and the soils' attitude was studied under the conditions of simulated rainfall. It was found that the instability of aggregates is negatively correlated with cation exchange capacity and the total specific surface of soils. Also the calcium carbonate content affects positively the aggregates instability. The process which seems to control dominantly the time that runoff occurs and the runoff and soil loss quantity, is the creation of surface seals with raindrop impact due to large calcium carbonate quantities that are met in the clay fraction.
\end{abstract}

KEY WORDS: Soil erosion, Rainfall simulation, Calcium carbonate

\section{INTRODUCTION}

It is widely recognized that the accelerated soil erosion is a serious global problem with significant financial and environmental consequences. Soil erosion effects occur both on- and off-site (Morgan, 1995). In the first case, the effects are particularly important on agricultural land, resulting in reduction of cultivable soil depth and fertility decline. The final consequence is a loss of productivity, which results to increased fertilizer consumption in order to maintain yields, but later threatens the food production and finally leads to land abandonment. In the second case, problems result from sedimentation on riverbeds and drainage networks which reduces their capacity, increases flooding risk, blocks irrigation canals and shortens the design life of water reservoirs. Several hydroelectric and irrigation projects have been destroyed as a consequence of erosion. Sediment is also a primary source of pollution and, through the chemicals absorbed to it, can increase the level of nitrogen and phosphorous in water bodies and results in eutrofication.

The major erosion types are those which happen 
Table 1. Some properties of soils under study

\begin{tabular}{|c|c|c|c|c|c|c|}
\hline & Soil 1 & Soil 2 & Soil 3 & Soil 4 & Soil 5 & Soil 6 \\
\hline Clay (\%) & 45.8 & 61.7 & 57.7 & 46.1 & 28.8 & 63.1 \\
\hline Silt (\%) & 22.8 & 26.7 & 28.8 & 21.9 & 25.6 & 11.8 \\
\hline Sand (\%) & 31.4 & 11.6 & 13.5 & 32.0 & 45.6 & 25.1 \\
\hline $\mathrm{pH}\left(\mathrm{H}_{2} \mathrm{O}, 1: 1\right)$ & 7.3 & 7.4 & 7.7 & 7.4 & 7.1 & 6.8 \\
\hline $\mathrm{CaCO}_{3}(\%)$ & 26.8 & 48.0 & 65.6 & 14.8 & 4.3 & 0.8 \\
\hline $\mathrm{OM}^{[1]}(\%)$ & 3.42 & 2.04 & 0.82 & 1.79 & 1.39 & 0.90 \\
\hline $\mathrm{CEC}^{[2]}(\mathrm{meq} / 100 \mathrm{~g})$ & 29.57 & 33.04 & 24.35 & 31.30 & 23.91 & 38.70 \\
\hline Instability Index $\beta$ & 0.072 & 0.117 & 0.217 & 0.130 & 0.284 & 0.048 \\
\hline $\operatorname{TSS}^{[3]}\left(\mathrm{m}^{2} \mathrm{~g}^{-1}\right)$ & 134 & 158 & 105 & 162 & 68 & 203 \\
\hline \multicolumn{7}{|c|}{$\begin{array}{l}{ }^{1} \text { Organic Matter } \\
{ }^{2} \text { Cation Exchange Capacity } \\
{ }^{3} \text { Total Specific Surface }\end{array}$} \\
\hline
\end{tabular}

due to rainwater and wind. Erosion caused by rainwater concerns Greece the most, because this mainly occurs. $25 \%$ of the country, approximately 3,500,000 hectares, have suffered serious erosion (De Ploey, 1983). This type of erosion is generally a function of rain erosivity on the one hand and soil erodibility on the other (Kinnell, 1973). The term "soil erodibility" refers to the ability or not of a soil to resist to the destructive action of factors that cause erosion (rain, wind, human, animals, etc.) (Zachar, 1982).

Research on erosion is conducted by several methods, the main of which include the use of experimental plots for the measurement of soil loss and surface runoff; the on-field observation of the erosion results (e.g. rills, gullies); the use of rain simulators by which the characteristics of natural rains of a region can be reproduced at specific time and place; and the use of laboratory methods where except the natural rain conditions, the soil conditions of a region are also simulated (FAO, 1965). As regards the soil erodibility, Gerrard (1981) reports that it can be estimated by measuring soil losses under controlled conditions and defining soil properties and interactions between them as erodibility indices. One of the commonly used erodibility indices is the specifically sized, stable in water, aggregates (Bryan, 1968).

In the present work, the erodibility characteristics of some calcareous soils of Central Greece were studied in the laboratory with particular emphasis on the role of carbonates in the formation of those characteristics.

\section{METHODOLOGY}

The instability of soil aggregates $2.0-4.7 \mathrm{~mm}$, in water, was studied for six calcareous soils from central Greece. Soil loss experiments were then conducted in the laboratory using a rain simulator, on four of these soils. Soil loss was measured and the attitude of soils during the experiments was studied. Samples of disturbed soil were used in the experiments.

\section{Soils}

The soils under study have been developed in tertiary calcareous and marly deposits under conditions of intense hilly relief. These soils present significant erosion problems since in quite large areas the calcareous substratum has been revealed. Their devotion to winter cereals and irrigated spring crops is quite extensive. The irrigation systems used deteriorate the problem. In country scale, the soils on tertiary deposits take up a significant area, which reaches $22 \%$ of the country according to Papamichos (1983).

The basic soil properties were determined by methods referred by Page et al. (1982). Aggregates' instability was determined using the "instability index $\beta$ " method (Valmis et al., 1988), which is based on the technique of wet sieving (Kemper, 1965). The total specific surface (TSS) determination was done using the method of Cihacek and Bremner (1979). Some of the soil properties are presented in Table 1. 


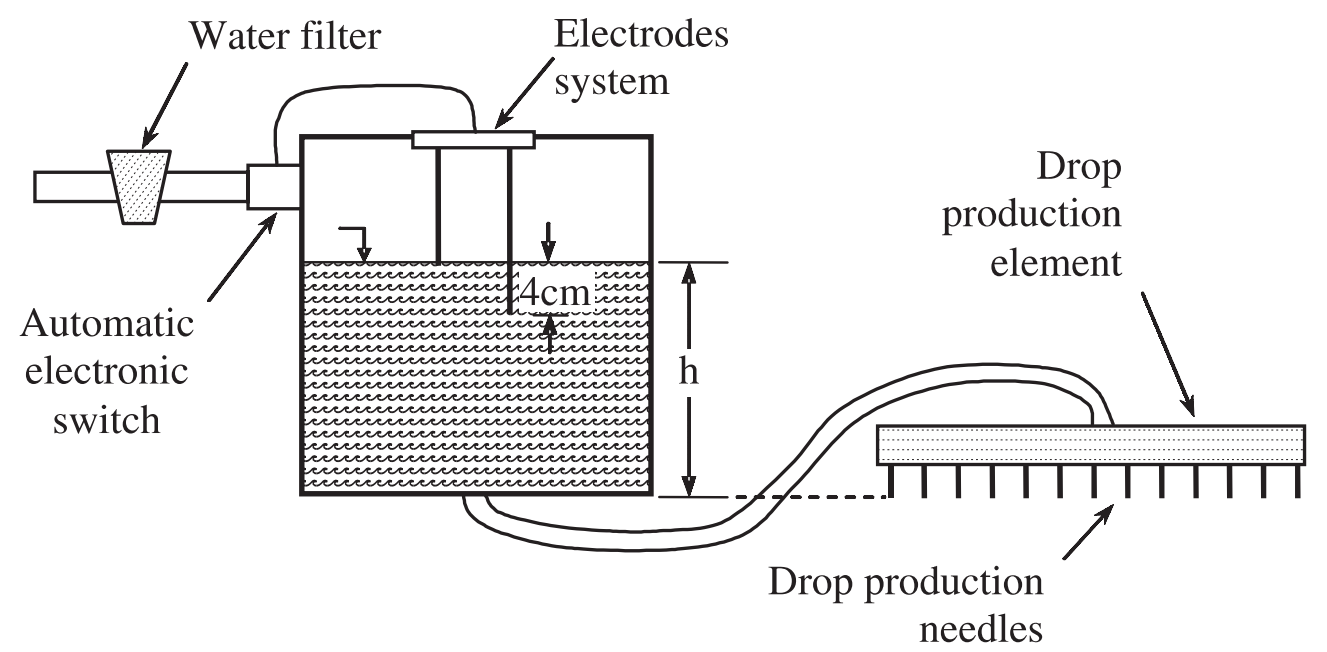

Figure 1. Diagrammatic representation of rain simulator's drop production system

\section{Rain simulator}

The constructed and used rain simulator belongs in the category of those where the rain drops form and fall from protruding needles, starting from zero velocity (Mutchler and Hermsmeier, 1965). The needles that used had an internal diameter of $0.58 \mathrm{~mm}$ and were set at the corners of squares with side dimension of $2.5 \mathrm{~cm}$ (Chow and Harbaugh, 1965). Drop production is a result of hydrostatic pressure, $\mathrm{h}$, that is gained by connecting the drop production system to a water container where the water level is kept at a constant height $( \pm 2 \mathrm{~cm})$ with an automated system of electrodes (Figure 1). In this way, the produced rain has a constant intensity.

Different rain intensity and drop size can be achieved by changing the hydrostatic pressure by moving the electrode system vertically. The produced raindrops fall on soil bed after travelling a distance of $7.5 \mathrm{~m}$, when they have obtained at least $95 \%$ of their maximum kinetic energy or their terminal velocity (Morgan, 1995). The soil sample is placed on a rectangular shaped bed sizing $1.90 \times 0.60 \times 0.20 \mathrm{~m}$. Using a pulley, the soil bed slope can be changed. For soil loss experiments, rain intensity of $28 \mathrm{~mm} \mathrm{~h}^{-1}$ with a drop diameter of $2.58 \mathrm{~mm}$ and soil slope $5 \%$ were used. The duration of every experiment was 4 hours.

\section{RESULTS AND DISCUSSION}

The phenomenon during which the primary soil particles are joined and form stable or unstable aggregates against the disruptive and detaching action of rainwater, has a very great importance for soil erosion since it defines the ease with which large aggregates fall apart in smaller ones, thus becoming more susceptible to erosion (Gerrard, 1981).

In the present study, in order to ascertain the effect of soil properties on instability of aggregates, the simple correlation coefficient $(r)$ of index $\beta$ with soil properties was calculated. The correlation was found to be statistically significant with cation exchange capacity $\left(\mathrm{r}=0.87^{*}\right)$ and the total specific surface $\left(\mathrm{r}=0.90^{*}\right)$ as shown in Figure 2.

As it is known, these two soil properties basically depend on the percentage and the type of clay minerals and also on the content in organic colloids and in colloidal oxides and hydroxides. Thus, it could be said that they represent simultaneously many factors that play a major role in water aggregate stability in the water (Alexiades, 1969; Brown, 1977).

No significant relation was found between index $\beta$ and the calcium carbonate content. But if it is considered that the same parent material could be the base for direct comparisons then, by observing the data of soils 1,2 and 3, which have been developed on the same parent material from marl, it could be concluded that their successively increasing instability (index $\beta$ : 0.072, 0.117 and 0.217 respectively), is possibly related to their successive increase of calcium carbonate content. In literature the role of carbonates in aggregate stability is presented in a controversial way. Allison 

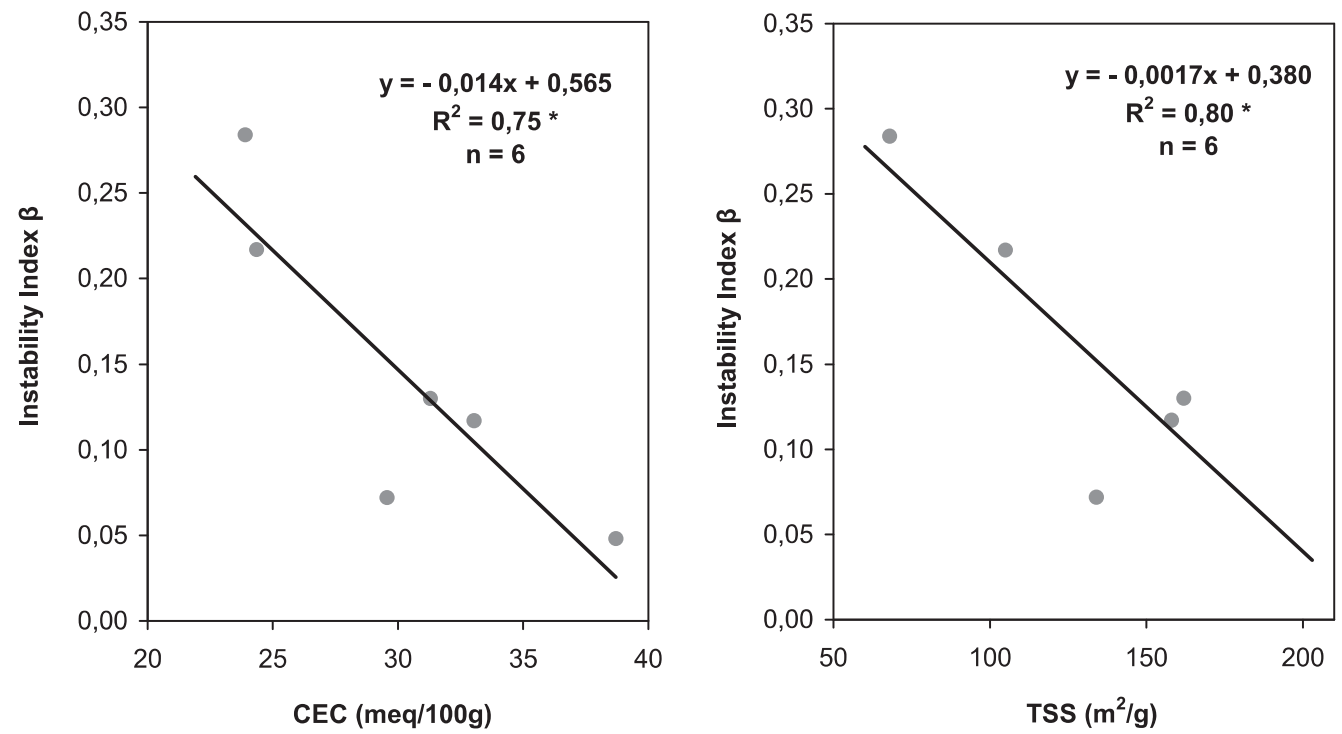

Figure 2. Relationship of instability index $\beta$ with cation exchange capacity (CEC) and the total specific surface (TSS)

(1968) reports that in semiarid and tropical red and yellow soils, carbonates play a very important role in aggregate stability, acting as cement. Similar observations have been made by Alexiades (1972). But Kalovoulos and Sylleos (1980) report that a great percentage of fine partitioned calcium carbonate leads to instability of aggregates in the water.

Data of soil loss experiments are presented in Table 2. Data show that for soils 1, 2, and 3, which have been developed in the same parent material, the time of runoff occurrence decreases respectively, while the runoff volume and the soil loss weight tend to increase.

During the experiment, it was observed that with raindrop impact, the aggregates do not fall apart in smaller ones but their diameter decreases continually until their elimination. This results in the creation of a sticky liquid soil mass, the illuviation of which ends with pore blocking and formation of an impermeable layer on soil surface (soil sealing) with runoff occurrence as a consequence. This process tended to be more intensive from soil 1 to soil 3 . Thus, the soil sealing creation played a determinative role in the definition of the runoff occurrence time, the runoff and the soil loss quantity. These soils are characterized by successively increasing total calcium carbonate content (Table 1). Also, the particle size analysis of calcium carbonate showed successively increasing proportional participation of calcium carbonate in clay fraction of soils. So, the fore described attitude of soils and the experimental results should be attributed rather to large, successively increasing, calcium carbonate quantities in very fine partition. It appears that the larger these quantities, the faster the formation of surface seal and runoff occurrence.

Table 2. Soil loss experimental data

\begin{tabular}{|c|c|c|c|c|}
\hline Soil & $\begin{array}{c}\text { Runoff occurrence } \\
\text { time (min) }\end{array}$ & $\begin{array}{c}\text { Runoff volume } \\
(\mathbf{L})\end{array}$ & $\begin{array}{c}\text { Vertical water } \\
\text { outflow }\end{array}$ & $\begin{array}{c}\text { Soil loss } \\
\left(\mathbf{g ~ m}^{-2}\right)^{*}\end{array}$ \\
\hline 1 & 115 & 8 & Yes & 221 \\
\hline 2 & 90 & 14 & No & 355 \\
\hline 3 & 85 & 16 & No & 451 \\
\hline 4 & 100 & 8 & Yes & 208 \\
\hline$*$ Dry weight & \multicolumn{3}{|}{} \\
\hline
\end{tabular}


Sample soil 4 showed higher stability and experienced the fewer losses. There was not absolute aggregate destruction observed, as to previous soils, nor impermeable seal formation. Vertical infiltration and water outflow from the bottom of soil bed were recorded instead. This soil is calcareous but with significantly lower calcium carbonate content (Table 1). Also the proportional participation of calcium carbonate in clay fraction was found to be significantly smaller than that of the other soils.

\section{CONCLUSIONS}

After the above discussion, as regards the erodibility characteristics of the studied calcareous soils, the following conclusions could be summarized:

- The soil properties which affect the instability of aggregates sizing $2.0-4.7 \mathrm{~mm}$ in the water, are the Cation Exchange Capacity and the Total Specific Surface. As these two parameters increase the aggregate instability decreases. As it is known, the above mentioned parameters depend on the percentage and the kind of clay minerals. The calcium carbonate seems to affect positively the aggregate instability.

- The process which dominantly controls the time that runoff occurs, the runoff and soil loss quantity when these soils are subjected to simulated rainfall, is the creation of surface seals with raindrop impact. This is rather due to large calcium carbonate quantities that are met in clay fraction. It appears that the larger the quantities, the faster the formation of surface seal and runoff occurrence.

\section{REFERENCES}

Alexiades, K.A. (1969), Soil Physics: I. Influence of Cations on the Formation of Water Stable Aggregates of Kaolinite and Montmorillonite, Scientific yearbook, Aristotle Univ. of Thessaloniki, School of Agriculture and Forestry (in Greek).

Alexiades, K.A. (1972), Clay, Inorganic and Organic Colloids of Soil, Aristotle Univ. of Thessaloniki, School of Agriculture and Forestry (in Greek).

Allison, F.E. (1968), Soil aggregation - Some facts and fallacies as seen by a microbiologist, Soil Sci., 106, 136-143.

Brown, W.K. (1977), Shrinking and swelling of clay, clay strength and other properties of clay soils and clays. In: Minerals in Soil Environments, Dixon J.B. and Weed S.B. (eds), Soil Sci. Soc. Am., Wisc., USA.

Bryan, R.B. (1968), The development, use and efficiency of indices of soil erodibility, Geoderma, 2, 5-26.

Chow, V.I. and Harbaugh, T.E. (1965), Raindrop production for laboratory watershed experimentation, $J$. Geophys. Res., 70, 6111-6119.

Cihacek, L.J. and Bremner, J.M. (1979), A simplified ethylene glycol monoethyl ether procedure for assessment of soil surface area, Soil Sci. Soc. Am. J., 43, 821-822.

De Ploey, J. (1983), Soil Conservation, an Anti-surplus Policy. In: Soil Erosion in The European Community, Chisci, G. and Morgan, R.P.C. (eds), Directorate - General for Agriculture, Brussels.

FAO (1965), Soil Erosion by Water, Agric. Div. Paper No 81, FAO, Rome.

Gerrard, J.A. (1981), Soils and Landforms, G. Allen and Unwin Ltd, London.

Kalovoulos, J.M. and Sylleos, N.G. (1980), Effect of Calcium on Soil Physical Properties, Aristotle Univ. of Thessaloniki, School of Agriculture and Forestry (in Greek with English abstract).

Kemper, W.D. (1965), Aggregate Stability. In: Methods of Soil Analysis, Black, C.A. (ed.), Part 1, Am. Soc. Agron., Agronomy 9, 511-519.

Kinnell, P.I.A. (1973), The problem of assessing the erosive power of rainfall from meteorological observations, Soil Sci. Soc. Am. Proc., 37, 617-620.

Morgan, R.P.C. (1995), Soil Erosion and Conservation, $2^{\text {nd }}$ ed., Longman, UK.

Mutchler, C.K. and Hermsmeier, L.F. (1965), A Review of Rainfall Simulators, ASAE Trans, 8, 63-65.

Page, A.L., Miller, R.H. and Keeny, D.R. (eds), (1982), Methods of Soil Analysis, Part 2, Chemical and Microbiological Properties, 2nd ed., Agronomy 9, Am. Soc. of Agron., Madison, WI.

Papamichos, N.T. (1985), Forest Soils, Aristotle Univ. of Thessaloniki, School of Agriculture and Forestry (in Greek).

Valmis, S., Kerkides, P. and Aggelides, S. (1988), Soil Aggregate Instability Index and Statistical Determination of Oscillation Time in Water, Soil Sci. Soc. Am. J., 52, 1158-1191.

Zachar, D. (1982), Soil Erosion, Elsevier Sci. Pub. Co., Amsterdam. 